\title{
Article \\ Friction Characteristics Analysis of Symmetric Aluminum Alloy Parts in Warm Forming Process
}

\author{
Jiansheng Xia ${ }^{1,2, *}$, Jun Zhao ${ }^{1, *}$ and Shasha Dou ${ }^{2}$ \\ 1 College of Mechanical Engineering, Yanshan University, Qinhuangdao 066004, China \\ 2 College of Mechanical Engineering, Yancheng Institute of Technology, Yancheng 224051, China; \\ lisadou@ycit.edu.cn \\ * Correspondence: xiajs@ycit.edu.cn (J.X.); zhaojun@ysu.edu.cn (J.Z.); \\ Tel.: +86-158-6198-8970 (J.X.); +86-335-807-4648 (J.Z.)
}

Citation: Xia, J.; Zhao, J.; Dou, S. Friction Characteristics Analysis of Symmetric Aluminum Alloy Parts in Warm Forming Process. Symmetry 2022, 14, 166. https://doi.org/ 10.3390/sym 14010166

Academic Editor: Marko Čanađija

Received: 14 December 2021

Accepted: 11 January 2022

Published: 14 January 2022

Publisher's Note: MDPI stays neutral with regard to jurisdictional claims in published maps and institutional affiliations.

Copyright: () 2022 by the authors. Licensee MDPI, Basel, Switzerland. This article is an open access article distributed under the terms and conditions of the Creative Commons Attribution (CC BY) license (https:// creativecommons.org/licenses/by/ $4.0 /)$.

\begin{abstract}
There are many typical symmetric large plastic deformation problems in aluminum alloy stamping. Warm stamping technology can improve the formability of materials and obtain parts with high-dimensional accuracy. Friction behavior in the stamping process is significant for the forming quality. An accurate friction coefficient is helpful in improving the prediction accuracy of forming defects. It is hard to obtain a unified and precise friction model through simple experiments due to the complicated contact conditions. To explore the effect of friction behavior on the forming quality, warm friction experiments of the AA6061 aluminum alloy and P20 steel with different process parameters were carried out using a high-temperature friction tester CFT-I (Equipment Type), including temperatures, the interface load, and sliding speeds. The variation curves of the friction coefficient with various parameters were obtained and analyzed. The results show that the friction coefficient increases with temperature and decreases with the sliding speed and load. Then, the influences of process parameters on the surface morphology of the samples after friction were observed by an optical microscope; adhesive wear occurred when the temperature increased, and the surface scratch increased and deepened with the increase in the load. Finally, the friction coefficient models of the speed and load were established by analyzing the data with Original software. Compared with the experimental and the finite element analysis results of the symmetrical part, the errors of the velocity friction model in thickness and springback angle are less than $4 \%$ and $5 \%$, respectively. The mistakes of the load friction model are less than $6 \%$ and $7 \%$, respectively. The accuracy of the two friction models is higher than that of the constant friction coefficient. Therefore, those coefficient models can effectively improve the simulation accuracy of finite element software.
\end{abstract}

Keywords: warm forming; friction coefficient; sliding speed; interface load; symmetrical part

\section{Introduction}

At present, lightweight technology can effectively improve fuel efficiency and has become the trend of the development of the automobile industry [1]. Because of its high strength-weight ratio, good corrosion resistance, and good thermal conductivity, aluminum alloy is the go-to alloy in the automobile, aerospace, and shipbuilding industries [2]. The formability of aluminum alloy is not as good as that of traditional low-carbon steel at room temperature [3]. There are many typical symmetric plastic deformation problems in the aluminum alloy forming process. These include drawing cylindrical parts, rounding holes, flanging circular plates, necking, expanding, bulging, etc. Compared with the cold forming process, warm forming can minimize springback, improve the formability of aluminum alloy and expand its application range [4]. Warm stamping is a new process that can effectively enhance the deep drawing formability of aluminum alloy, increase the strength of materials, reduce the internal stress, reduce the springback, and significantly improve the surface quality and forming accuracy [5]. The warm stamping of aluminum alloys is a 
complicated thermal-mechanical coupling process, and friction behavior is the critical factor influencing the forming quality and die life [6]. The rheological stress and forming force of hot aluminum sheets in different areas change, making the friction more complex. The actual friction coefficient constantly changes. Usually, the Coulomb friction law or constant friction factor model is widely used in sheet metal forming numerical simulation software, and the friction factor is often input as a regular [7], which results in a deviation between the actual value and the numerical simulation results. However, the friction behavior of the stamping process is quite complex, including the changing interaction variables in the forming process, deformation, forming speed, materials, surface roughness, tool geometry, etc. Therefore, to improve the accuracy of numerical simulation results, it is necessary to profoundly and systematically study the friction and contact problems in the forming process of aluminum alloy sheets and obtain the accurate friction factor of the aluminum alloy under different process conditions.

Some researchers developed the sliding friction and designed a tester to obtain the friction coefficient at high temperatures. Yoshikiyo Tamai et al. [8] studied the effects of positive pressure, sliding speed, and punch stroke on the friction coefficient through the friction measuring device, and found that the friction coefficient decreases with the increase in positive pressure and sliding speed, and slightly increases with the rise of punch stroke. Imanol Gil et al. [9] studied the influences of positive pressure on the friction coefficient of DX54D in the forming process by using a self-designed friction measuring device. They proposed that the friction coefficient of the three materials showed the same variation law. They all decreased gradually with the increase in positive pressure. Dou et al. [10] established friction experiments on AA6111 aluminum alloy under warm forming conditions and obtained the friction coefficient model related to speed. Dohda et al. [11] reviewed the friction during metal high-temperature forming. He summarized the friction coefficient of the plate and bar formed under different test equipment at high temperatures. Marzouki et al. [12] carried out the pin-disk friction experiment at $400{ }^{\circ} \mathrm{C}$ and investigated the effectiveness of varying tool coatings in hot stamping. Andrzej Matuszak et al. [13] simulated the friction contact state between a steel plate and tool during the forming process. They established a linear regression model to predict the dispersion effect. However, most researchers analyzed only hot or cold forming and did not consider warm forming too much. They did not verify the friction coefficient model by combining finite element software and the actual test. Therefore, they could not accurately obtain the friction coefficient of symmetrical parts in the warm forming process.

In this work, we use a CFT-I friction tester to measure the friction coefficient between aluminum alloy (AA 6061) and P20 steel. Then, the more practical coefficient models are established based on experimental parameters. The surface morphology of samples is observed and analyzed. Finally, the model effectiveness is verified by combining finite element software and actual experiments with the typical symmetrical part.

\section{Materials and Methods}

\subsection{Materials}

The axisymmetric material used in this study was AA6061-T6 aluminum alloy with a thickness of $1 \mathrm{~mm}$ produced by Southwest Aluminum Co., Ltd. (Chongqing, China). The chemical composition is shown in Table 1 . The sheet was cut into samples with $10 \mathrm{~mm} \times 20 \mathrm{~mm}$. The hardness of P20 after quenching and tempering reached HRC56, after which surfaces were polished with 240,400 , and 800 grits sandpaper in turn to obtain the same final surface finish and the contact surface roughness. $R a$ was $0.2 \sim 0.6 \mu \mathrm{m}$ and $0.8 \sim 1.3 \mu \mathrm{m}$, respectively. Then, the samples were immersed in acetone solution to prevent the surface from contaminants with oil; then, they were cleaned, dried, and sealed. Please refer to Figure 1. 
Table 1. Chemical composition of AA6061-T6 aluminum alloys (wt.\%); data from [14].

\begin{tabular}{ccccccccccc}
\hline Components & Si & Fe & Cu & Mg & Zn & Ti & Cr & Mn & Al \\
\hline Mass fraction & 0.62 & 0.33 & 0.17 & 0.90 & 0.02 & 0.02 & 0.17 & 0.06 & Rest \\
\hline
\end{tabular}

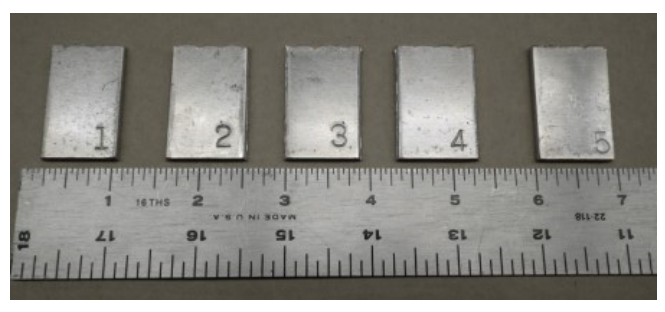

(a)

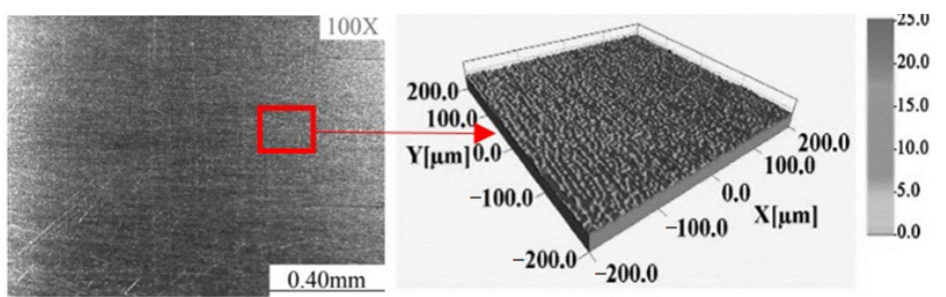

(b)

Figure 1. A fiction test sample of AA6061 aluminum alloy and P20 steel. (a) Friction specimens; (b) Surface topography of P20.

\subsection{Test Equipment}

A CFT-I tester (Zhongke Kaihua Technology Development Co., Ltd., Lanzhou, China) was used as shown in Figure 2a. The instrument can measure various friction experiments at varying temperatures, of which the working principle is shown in Figure 2b. Before the repeated symmetrical movement, the heating chamber was fixed on the test platform to achieve reciprocating motion. Then, the sample was heated in the furnace. The platform installed with the die sample could move up and down along the $Z$-axis during the test. After moving down, the computer program applied the normal load to the contact surface. The die block remained fixed during the friction movement, and the platform with the heating furnace and the aluminum alloy disk sample repeatedly moved along the $x$-axis. The equipment parts are shown in Figure 2c. Firstly, the temperature controller raised the temperature to be lower than the target temperature at a higher rate, then raised the temperature to the target temperature at a lower rate. The temperature controller could ensure uniform temperature distribution of the sample for $5 \mathrm{~min}$ [15]. Then, it immediately carried out the friction test. After the test, the pieces were removed from the friction disc and cooled naturally at room temperature (Figure $2 \mathrm{~d}$ ). The reciprocating platform with the heating furnace and aluminum alloy disk sample moved reciprocally along the $x$-axis, driven by the servo motor.

The force sensor recorded the load and tangential friction force in real time, transmitting measured data to the computer during the friction process. Coulomb's law Equation was used to calculate the real-time friction coefficient $\mu$.

\subsection{Experimental Arrangement}

The friction mechanism of aluminum alloy in the warm forming process is complex, with many influencing factors, including speed, temperature, load, stroke, and surface roughness. The orthogonal experiment measured the friction coefficient under different process parameters, including temperature, average load, sliding speed, boundary lubrication, and sliding stroke (refer to Table 2). Boundary lubrication sprayed high-temperature anti-oxidant lubricant (molybdenum disulfide and boron nitride) evenly on the sheet metal surface to form a thin oil film; the thickness was less than $0.1 \mu \mathrm{m}$. 


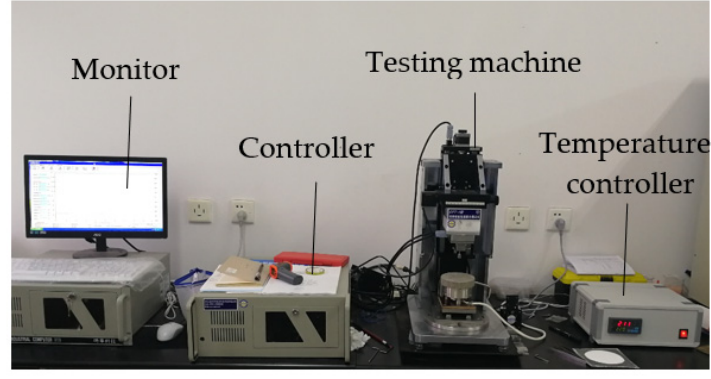

(a)

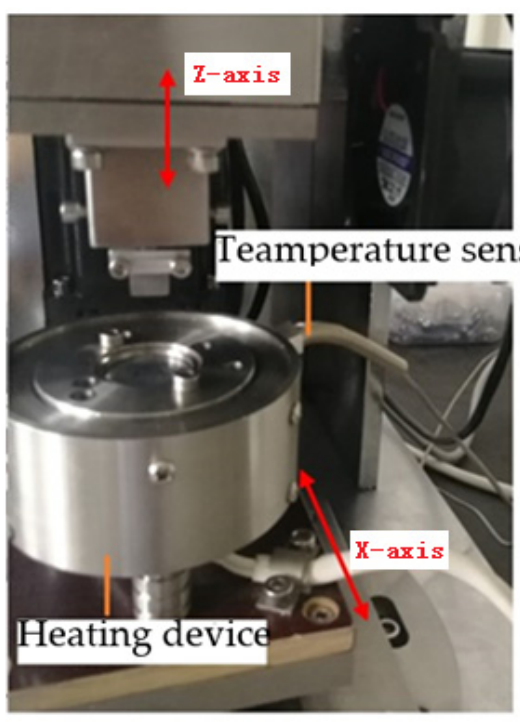

(c)

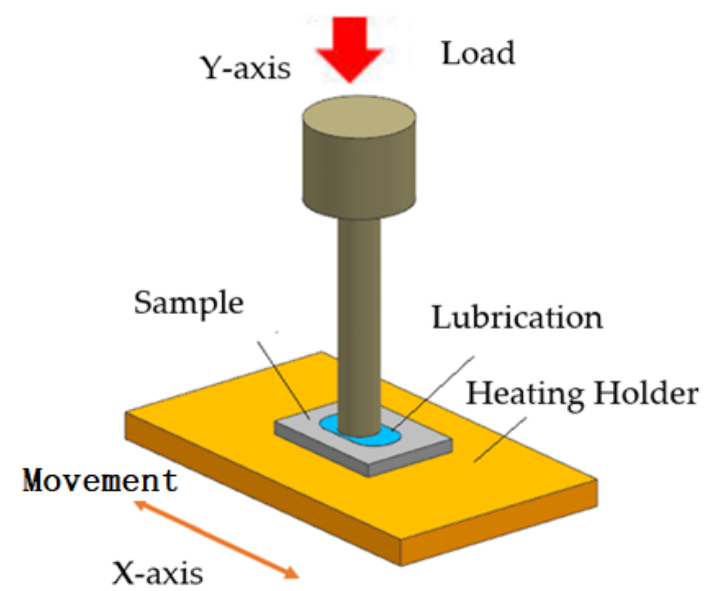

(b)

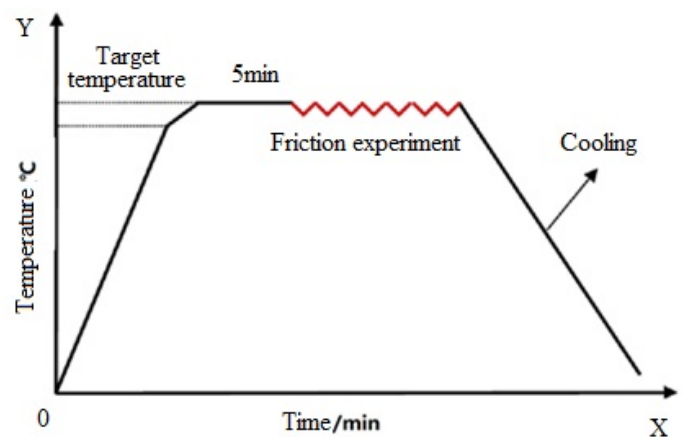

(d)

Figure 2. CFT-I multifunctional material surface comprehensive performance tester. (a) Friction test; (b) friction test principle; (c) Detailed parts of friction device; (d) temperature control principle.

Table 2. Parameter setting of AA6061 aluminum alloy friction test.

\begin{tabular}{ccccc}
\hline $\begin{array}{c}\text { Temperature } \\
\left({ }^{\circ} \mathbf{C}\right)\end{array}$ & $\begin{array}{c}\text { Load } F_{z} \\
(\mathbf{N})\end{array}$ & $\begin{array}{c}\text { Speed } \boldsymbol{V} \\
(\mathbf{m m} / \mathbf{s})\end{array}$ & $\begin{array}{c}\text { Stroke } \boldsymbol{L} \\
(\mathbf{m m})\end{array}$ & Lubrication \\
\hline 25 & 10 & 20 & 20 & Boundary Lubrication \\
\hline 100 & 20 & 30 & 20 & Boundary Lubrication \\
\hline 150 & 30 & 40 & 20 & Boundary Lubrication \\
\hline 200 & 40 & 50 & 20 & Boundary Lubrication \\
\hline 250 & 50 & 60 & 20 & Boundary Lubrication \\
\hline
\end{tabular}

\section{Results and Discussion}

\subsection{Relationship between Temperature and Friction}

(1) The relationship between friction coefficient and temperature

Under boundary lubrication, the sliding speed of $30 \mathrm{~mm} / \mathrm{s}$, and the load of $20 \mathrm{~N}$, we measured the friction coefficients between the aluminum alloy and tool. The data were read twice per second with varying temperatures $\left(25^{\circ} \mathrm{C}, 100{ }^{\circ} \mathrm{C}, 150{ }^{\circ} \mathrm{C}, 200^{\circ} \mathrm{C}\right.$, and $\left.250{ }^{\circ} \mathrm{C}\right)$. 
The value trend is shown in Figure 3, indicating that time and temperatures influenced the friction coefficient. The curve consisted of three stages. (I) The sharp increase stage (0 2 s). In the initial stage, the friction force increased rapidly to near 0.2 . The main reason was the conversion from static friction to dynamic friction. The velocity changed from unstable to stable, which overcame the maximum static friction. (II) The decline slowly stage (2 4 s). The friction coefficient decreased slightly by $0.02 \sim 0.05$. The main reason was that the friction coefficient changed from static friction to dynamic friction after the relative sliding of the plate, and the friction coefficient decreased somewhat. (III) The rise slowly stage (4 15 s). The lubricant on the aluminum alloy surface reduced slightly with further increased friction time. The friction produces surface micro convex bodies embedded, increasing the actual contact area and the slow increase in friction coefficient. In addition, with the growth of temperature, the friction coefficient also increased. The rise in the friction coefficient was primarily due to the increase in temperature that led to the decrease in lubricating oil viscosity, the destruction of the oxide film on the surface of the aluminum alloy, and the transfer adhesion of the aluminum alloy's surface.

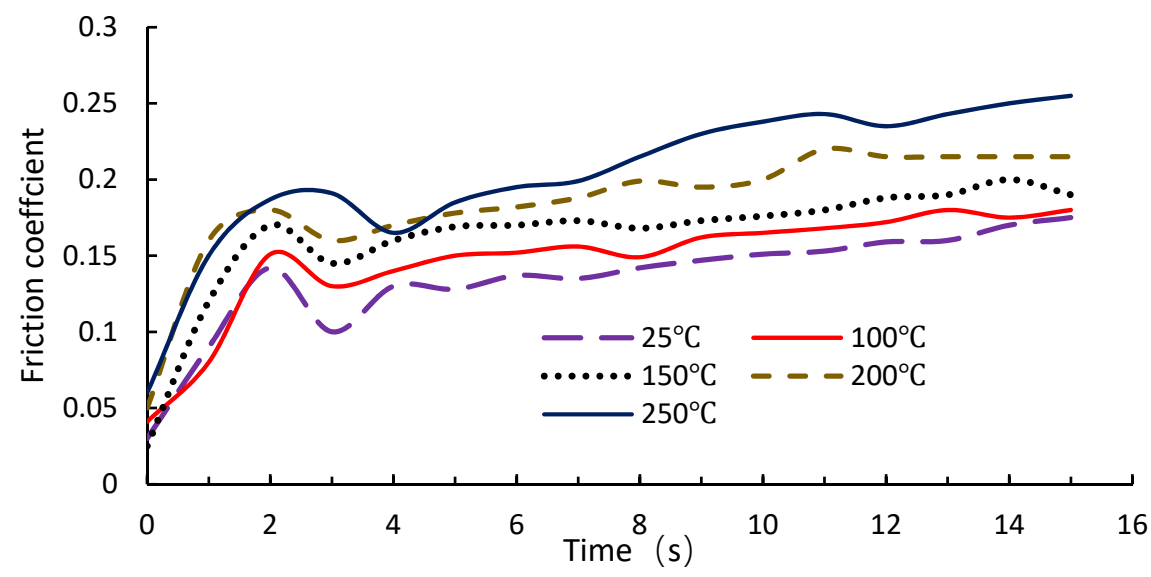

Figure 3. Variation curves of the friction coefficient with time at different temperatures.

The average friction values were calculated by taking the first $5 \mathrm{~s}$, and the variation curve of friction coefficient with the temperature is shown in Figure 4. The curve had three major stages: the slow rise stage (from $25^{\circ} \mathrm{C}$ to $100{ }^{\circ} \mathrm{C}$ ), where the friction coefficient increased from 0.13 to 0.155 ; the rapid increase stage (from $100{ }^{\circ} \mathrm{C}$ to $200{ }^{\circ} \mathrm{C}$ ), 0.155 to 0.195 ; the steady stage (from $200^{\circ} \mathrm{C} 250^{\circ} \mathrm{C}$ ), where the friction coefficient eventually increased slowly with the further growth of temperature.

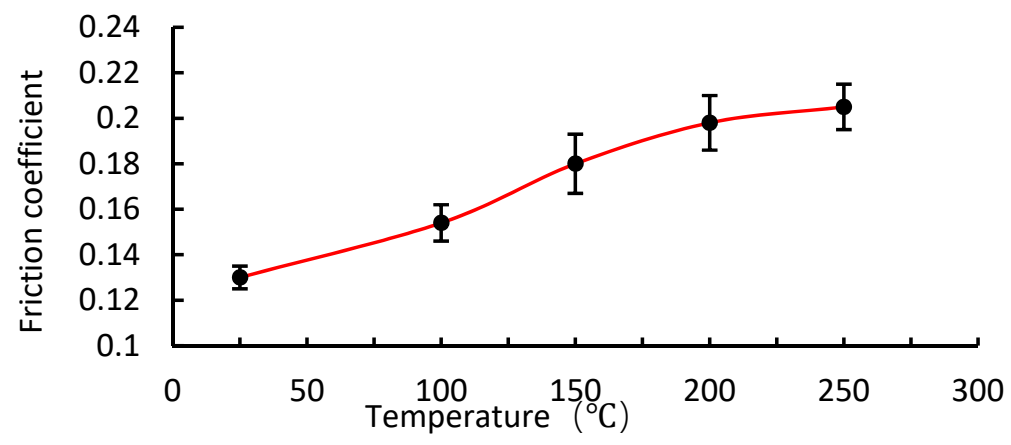

Figure 4. Friction coefficient curve with temperature.

(2) The surface morphology changes with temperature

The surface morphology of aluminum alloy after friction at different temperatures was analyzed using a VK-X100 laser scanning microscope (KEYENCE, Osaka, Japan). Refer to Figure 5. When the temperature was $25^{\circ} \mathrm{C}$, there were a few scratches on the surface of 
aluminum alloy, abrasive wear, accompanied by a small amount of fine abrasive particles. When the temperature was $100{ }^{\circ} \mathrm{C}$, the scratches on the surface of the aluminum alloy increased, the depth increased, and the wear particles decreased. When the temperature was $150{ }^{\circ} \mathrm{C}$, the scratches increased, and the depth also increased. When the temperature was $200^{\circ} \mathrm{C}$, the scratches reduced, and the surface quality was relatively good, indicating a slight adhesive wear. When the temperature rose to $250^{\circ} \mathrm{C}$, the adhesive wear on the aluminum alloy surface intensified, and the metal fell off and tore on the surface, resulting in severe adhesive wear, as shown in Figure 5d. By analyzing the surface morphology at different temperatures and considering the production cost and heating conditions in actual production, the warm temperature was chosen to be $200^{\circ} \mathrm{C}$.

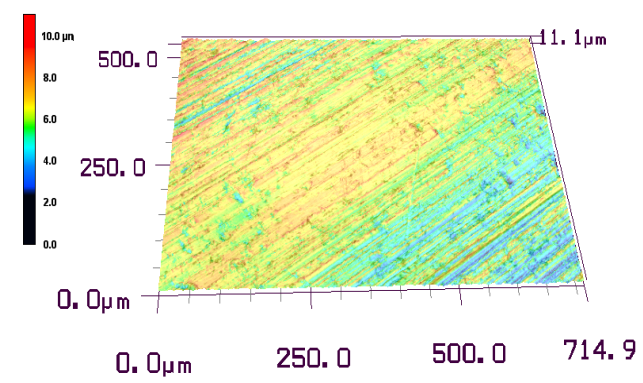

(a)

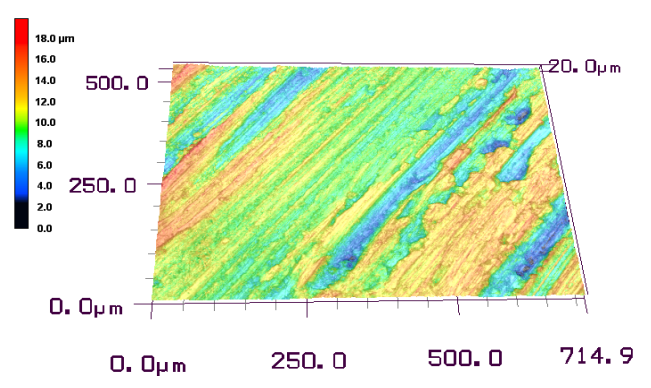

(c)

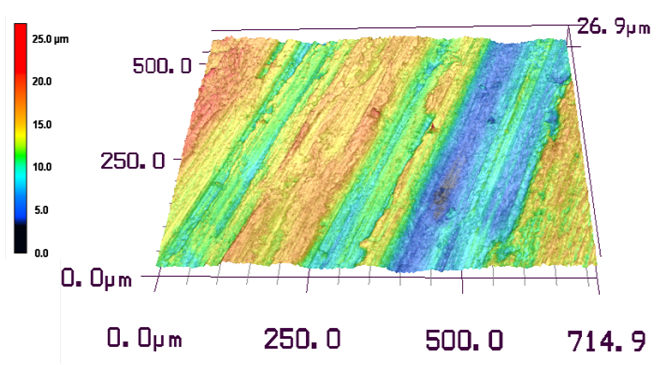

(e)

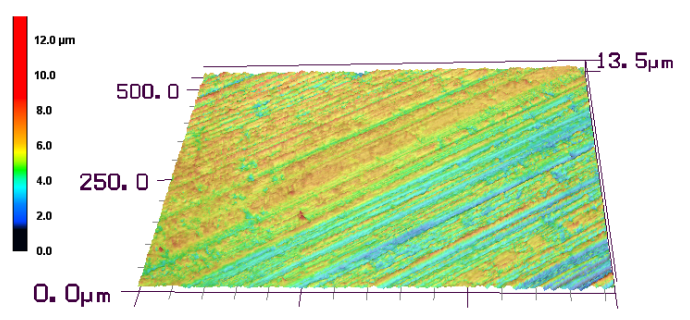

$0.0 \mu \mathrm{m}$

250. 0

500. $0 \quad 714.9$

(b)

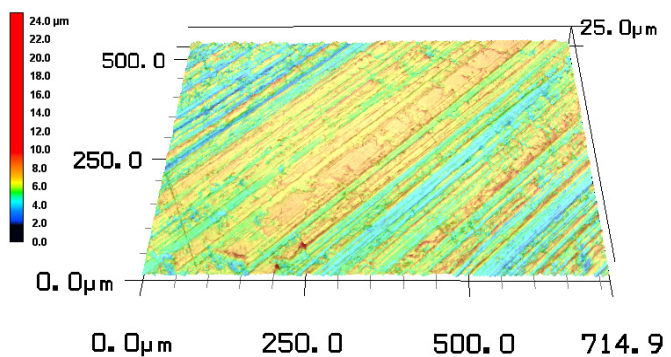

(d)

Figure 5. Surface morphology at different temperatures. (a) $\mathrm{T}=25^{\circ} \mathrm{C}$; (b) $\mathrm{T}=100{ }^{\circ} \mathrm{C}$; (c) $\mathrm{T}=150{ }^{\circ} \mathrm{C}$; (d) $\mathrm{T}=200{ }^{\circ} \mathrm{C}$; (e) $\mathrm{T}=250{ }^{\circ} \mathrm{C}$.

\subsection{Relationship between Sliding Speed and Friction}

(1) Friction coefficient vs. speed

With the boundary lubrication condition, the temperature was $200^{\circ} \mathrm{C}$, the load was $20 \mathrm{~N}$, and five different speeds $(20 \mathrm{~mm} / \mathrm{s}, 30 \mathrm{~mm} / \mathrm{s}, 40 \mathrm{~mm} / \mathrm{s}, 50 \mathrm{~mm} / \mathrm{s}$, and $60 \mathrm{~mm} / \mathrm{s})$ were carried out. The variation curves of the friction coefficient are presented (Figure 6) and showed that the five friction curves had the same inclination. The front increased rapidly and decreased slightly, rose, and, finally, entered a relatively constant stage. The reason was a layer of foreign matter on the friction surface, usually including moisture, metal oxides, and deposited lubricating materials. Aluminum oxidation is fast since it has a very high oxygen affinity. Therefore, in the initial stage, the oxide film easily separated the 
surfaces of the two materials, the two metals almost had no actual contact, and the oxide film had a low shear strength. The film (deposited layer) broke during the initial friction, cleaning the surface contact and increasing adhesion between the contact surfaces. The inclusion of trapped abrasive particles and the roughness of the matrix led to the increase in the plowing effect, which increased the friction [16].

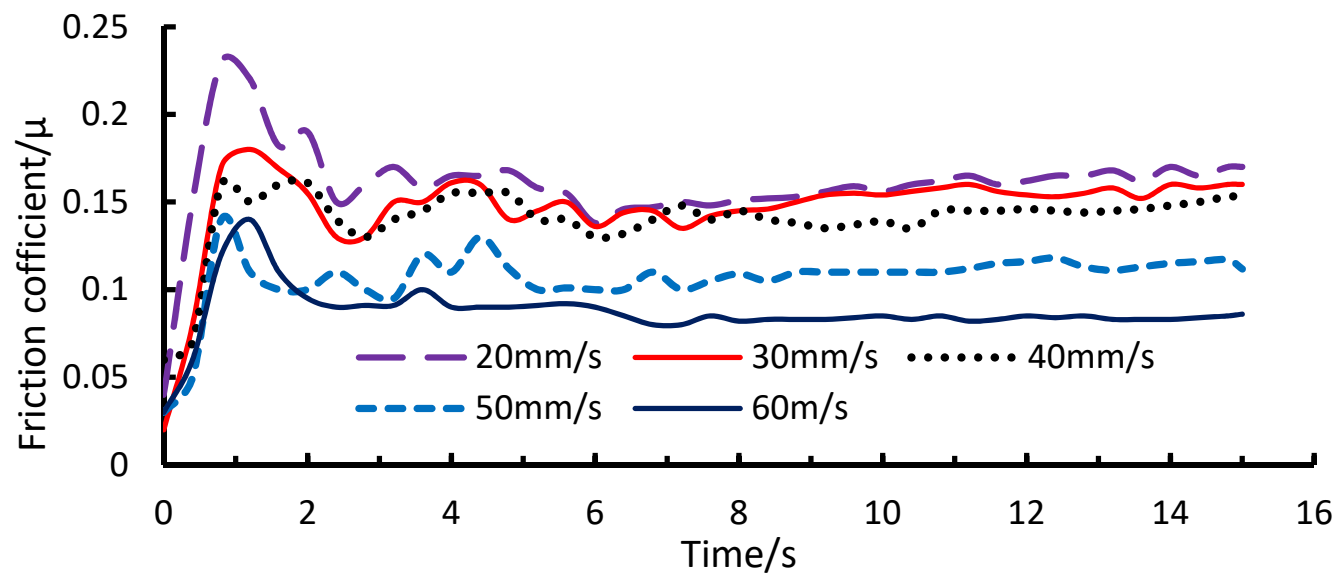

Figure 6. Relation curves between speed and friction.

The surface plowing increased the temperature and deformed the surface layer, resulting in metal loss. In addition, the increase in adhesion and hardening may have also played a particular role. After a certain period of friction, the growth of roughness and other parameters could reach a specific steady-state value, so the friction coefficient remained unchanged in the remaining time. The friction coefficient gradually decreased with the increase in sliding speed due to the change of the shear rate. These materials had greater strength at higher shear strain rates, resulting in a lower actual contact area and lower friction coefficient [17].

(2) Surface morphology influenced by speed

After the friction experiment, the friction surface morphology was analyzed with different speeds $(20 \mathrm{~mm} / \mathrm{s}, 30 \mathrm{~mm} / \mathrm{s}, 50 \mathrm{~mm} / \mathrm{s}$, and $60 \mathrm{~mm} / \mathrm{s})$ (Figure 7). When the speed was $20 \mathrm{~mm} / \mathrm{s}$, some furrow wear and adhesive wear occurred on the surface of the aluminum alloy. There was a small amount of fine abrasive particles, resulting in the damage and wear of the surface oxide layer, more scratches, and a reduced contact area. When the speed was $30 \mathrm{~mm} / \mathrm{s}$, the scratches reduced from $9.4 \mu \mathrm{m}$ to $8.7 \mu \mathrm{m}$, and some adhesion pits and scratches formed on the surface. When the speed was $50 \mathrm{~mm} / \mathrm{s}$, the scratches decreased from $8.7 \mu \mathrm{m}$ to $7.6 \mu \mathrm{m}$, and a small number of adhesion pits were on the surface. When the speed was $60 \mathrm{~mm} / \mathrm{s}$, the scratches reduced from $7.6 \mu \mathrm{m}$ to $6.6 \mu \mathrm{m}$. In conclusion, with the increase in sliding speed, a thin film protective layer formed on the sheet surface, which reduced the contact area and decreased the friction coefficient. 


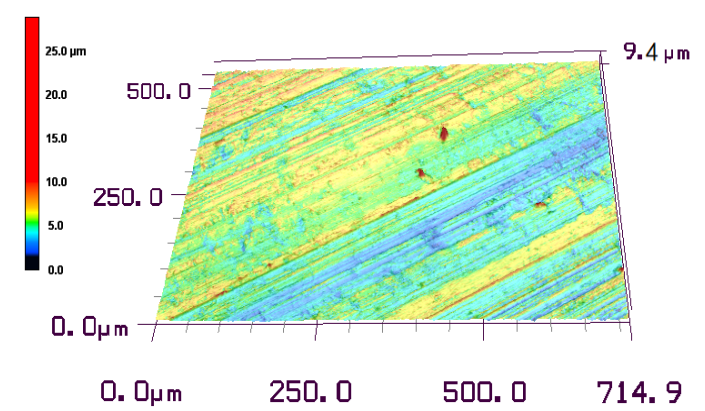

(a)

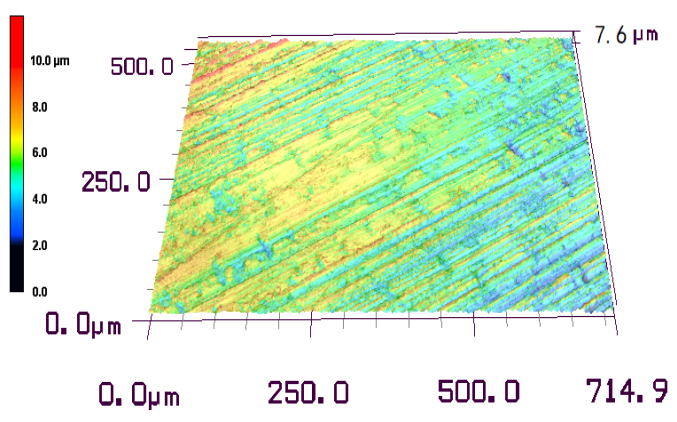

(c)

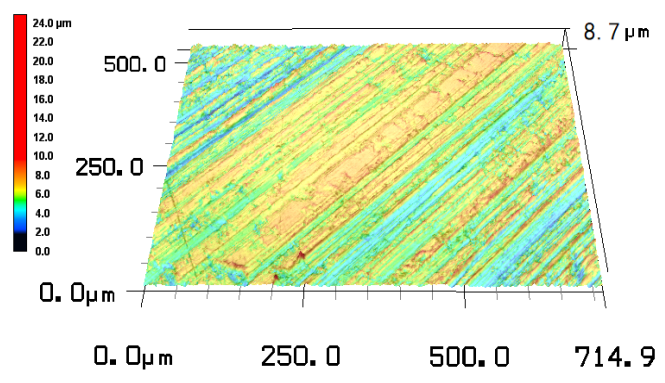

(b)

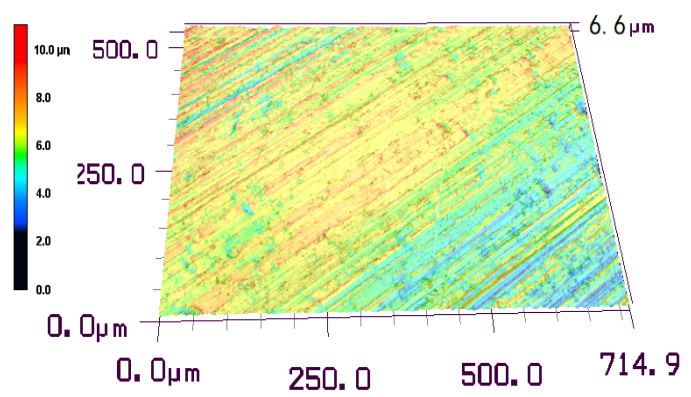

(d)

Figure 7. Surface morphology at different sliding speeds. (a) $v_{1}=20 \mathrm{~mm} / \mathrm{s} ;$ (b) $v_{2}=30 \mathrm{~mm} / \mathrm{s}$; (c) $v_{3}=50 \mathrm{~mm} / \mathrm{s} ;(\mathbf{d}) v_{4}=60 \mathrm{~mm} / \mathrm{s}$.

\subsection{Relationship between Load and Friction}

(1) Friction coefficient vs. load

When the temperature was $200{ }^{\circ} \mathrm{C}$ and the speed was $20 \mathrm{~mm} / \mathrm{s}$, the relationship between the load and friction coefficient was measured under five groups of different loads $(10 \mathrm{~N}, 20 \mathrm{~N}, 30 \mathrm{~N}, 40 \mathrm{~N}$, and $50 \mathrm{~N})$, as shown in Figure 8.

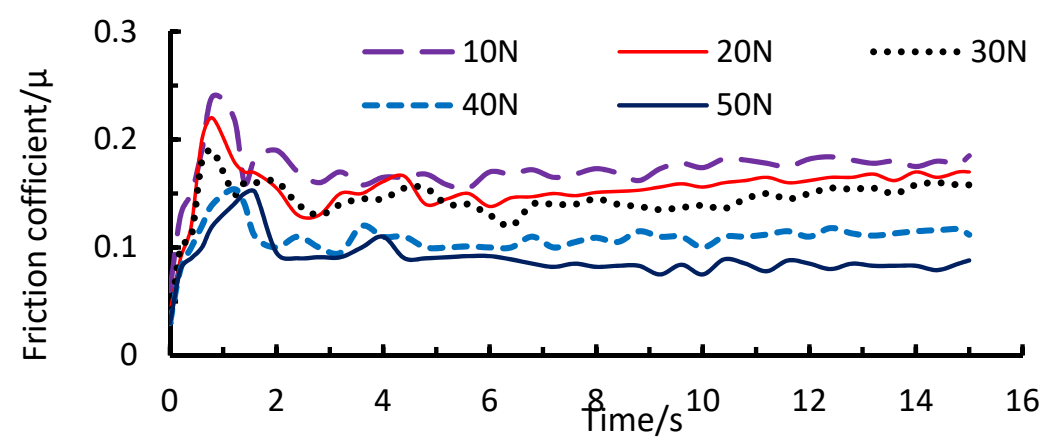

Figure 8. Relation curve between load and friction.

The figure shows that the friction coefficient first rose sharply, then decreased and rose, finally, maintained near an equilibrium value, and fluctuated up and down. Analyses of the reason showed that an increase in load would increase the wear and loss of metal, damage the surface layer, and increase the contact strength between surfaces. In addition, the friction between surfaces would increase the temperature. This effect would increase adhesion and the deformation of the surface layer, resulting in further metal loss-finally, the friction coefficient decreased with the increase in the average load.

(2) Surface morphology influenced by load

When the temperature was $200{ }^{\circ} \mathrm{C}$ and the speed was $20 \mathrm{~mm} / \mathrm{s}$, the effects of different normal loads $(10 \mathrm{~N}, 20 \mathrm{~N}, 30 \mathrm{~N}, 40 \mathrm{~N}$, and $50 \mathrm{~N})$ on the surface micromorphology were observed and analyzed in Figure 9. 

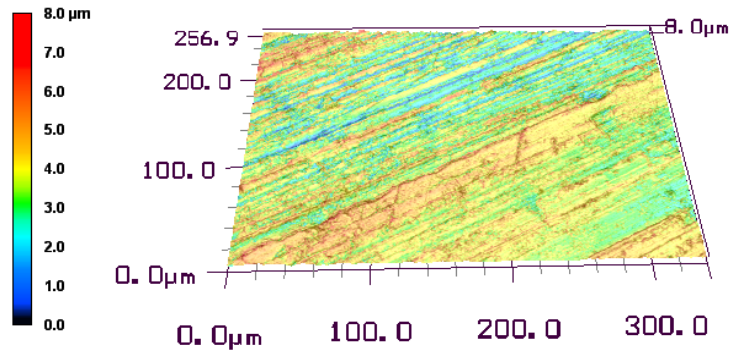

(a)

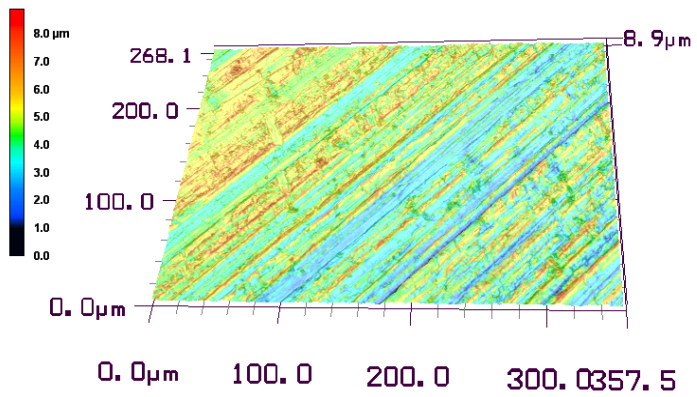

(c)
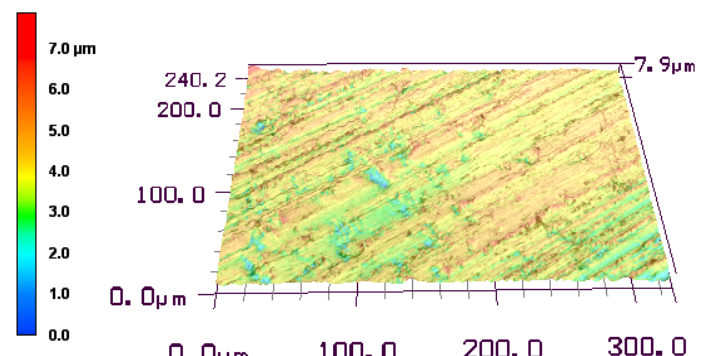

$0.0 \mu \mathrm{m}$

100.0200 .0

300. 0

(b)

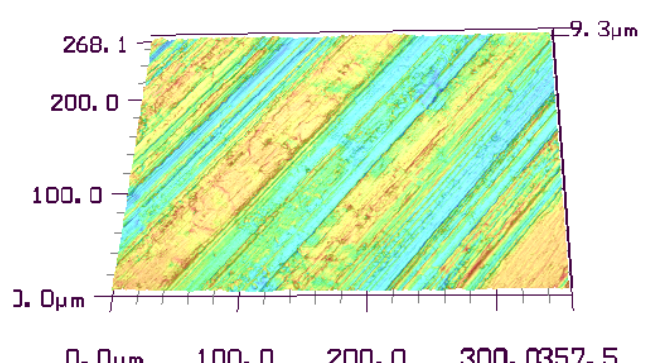

(d)

Figure 9. Surface morphology at different normal loads. (a) $10 \mathrm{~N}$; (b) $20 \mathrm{~N}$; (c) $40 \mathrm{~N}$; (d) $50 \mathrm{~N}$.

From the surface topography, the friction coefficient decreased with the increase in normal force, which was consistent with the principle of tribology. The wear mechanism was the rise of load which led to an increase in metal wear and loss, wear and wear rate, and surface roughness. In addition, it led to a rise of surface temperature and the generation of friction heat on the contact surface, which reduced the material strength and gradually flattened the protrusion. The high temperature would produce a stable state and high sliding speed, reduce the shear force, and reduce the friction coefficient. In the friction process, with the increase in the normal load, the volume wear increased, the surface roughness increased, and a large amount of wear debris entered the furrow, increasing the actual contact area.

\subsection{Variable Friction Coefficient Model}

(1) Friction model with velocity

When the temperature was $200{ }^{\circ} \mathrm{C}$, friction experiments were carried out under different sliding velocity $(20 \mathrm{~mm} / \mathrm{s}, 30 \mathrm{~mm} / \mathrm{s}, 40 \mathrm{~mm} / \mathrm{s}, 50 \mathrm{~mm} / \mathrm{s}$, and $60 \mathrm{~mm} / \mathrm{s})$ and different normal loads $(10 \mathrm{~N}, 20 \mathrm{~N}, 30 \mathrm{~N}, 40 \mathrm{~N}$, and $50 \mathrm{~N})$. The measured friction coefficients are in Table 3.

Table 3. Friction coefficient under different velocities and loads.

\begin{tabular}{cccccc}
\hline Speed/(mm/s) & 20 & $\mathbf{3 0}$ & $\mathbf{4 0}$ & $\mathbf{5 0}$ & $\mathbf{6 0}$ \\
\hline 10 & & & & & 0.080 \\
\hline 20 & 0.161 & 0.129 & 0.106 & 0.091 & 0.075 \\
\hline 30 & 0.139 & 0.122 & 0.098 & 0.084 & 0.073 \\
\hline 40 & 0.128 & 0.113 & 0.095 & 0.081 & 0.069 \\
\hline 50 & 0.121 & 0.109 & 0.090 & 0.077 & 0.067 \\
\hline
\end{tabular}

The relationship curves between friction coefficient and sliding speed are shown in Figure 10. The friction coefficient decreased with the increase in sliding velocity, and the 
curve trend conformed to the inverse function. Therefore, the relationship expression of the inverse function was:

$$
\mu=\frac{a}{v+b}+c
$$

where $\mu$ is the friction coefficient, $v$ is the sliding speed, and $a, b$, and $c$ are constants.

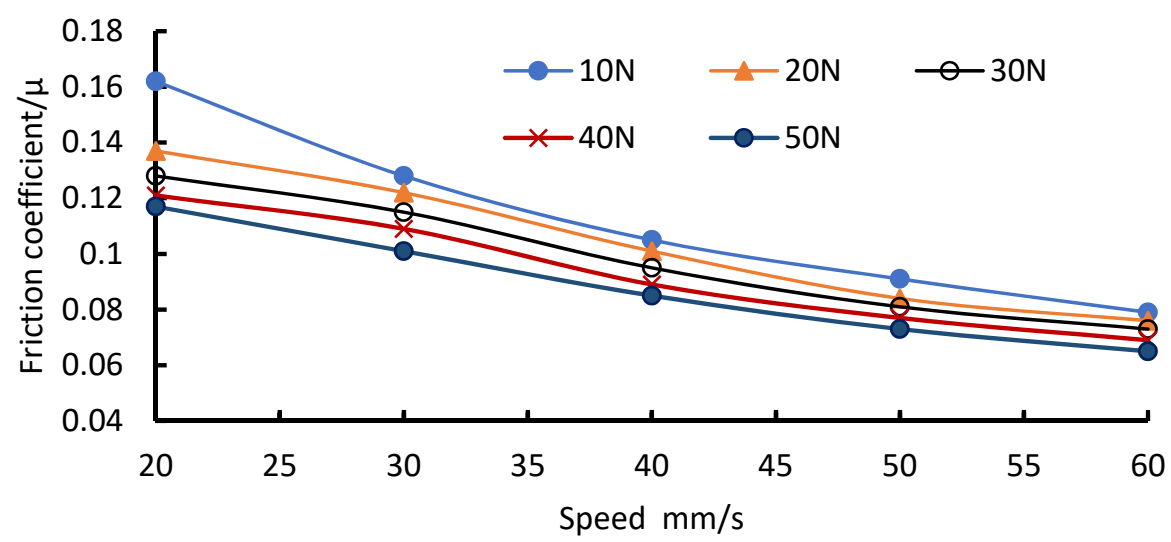

Figure 10. The relationship between friction coefficient and sliding speed.

The inverse function was used to fit the friction coefficient and sliding speed with the Origin software, and the fitting results under different loads $(10 \mathrm{~N}, 20 \mathrm{~N}, 30 \mathrm{~N}, 40 \mathrm{~N}$, and $50 \mathrm{~N})$ were as shown in Figure 11.

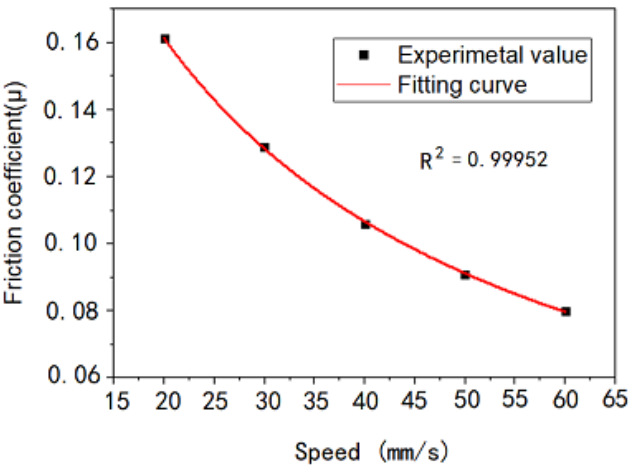

(a)

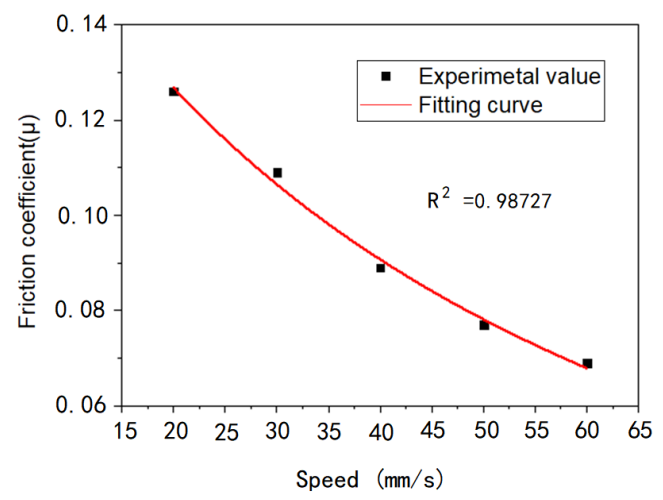

(c)

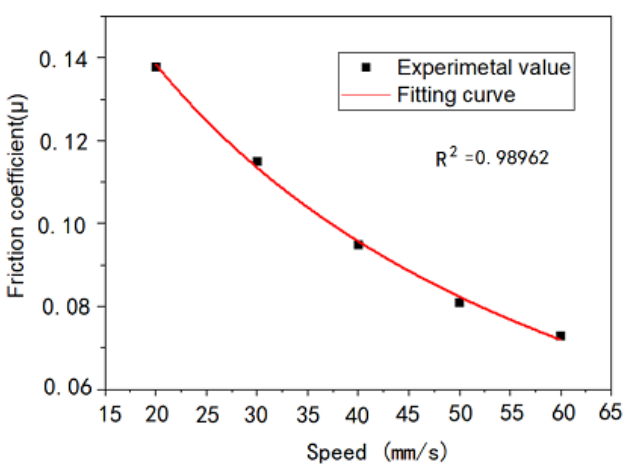

(b)

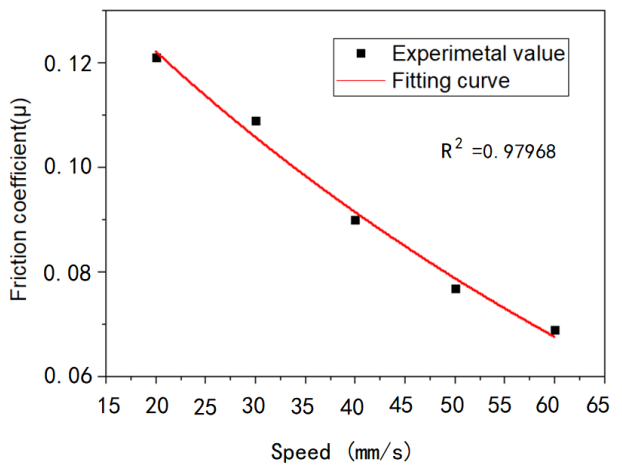

(d)

Figure 11. Cont. 


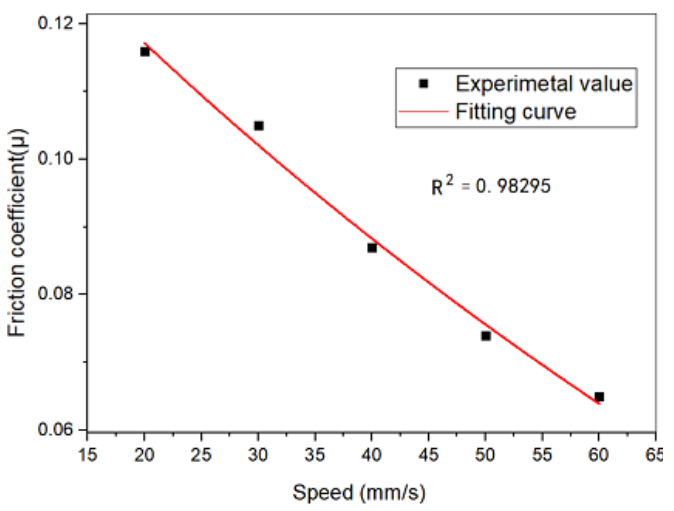

(e)

Figure 11. The fitting curve of friction coefficient under different loads. (a) $10 \mathrm{~N}$; (b) $20 \mathrm{~N}$; (c) $30 \mathrm{~N}$; (d) $40 \mathrm{~N}$; (e) $50 \mathrm{~N}$.

The reasonable degree of $a, b$, and $c$ values and equations under the five different load conditions are shown in Table 4 . The fitting degree between the inverse function and the actual value was more than 0.95 , indicating that the fair values of $a, b$ and $c$ was effective. In order to verify the correctness of the model, with a constant load of $20 \mathrm{~N}, a=6.28091$, $b=19.1928, c=0.0002$, and the fitting degree of the equation was 0.99952 . Therefore, the friction coefficient equation was:

$$
\mu=\frac{6.28091}{v+19.1928}+0.0002
$$

Table 4. Coefficient values $(a, b, c)$ and fitting degree of fitting under different loads.

\begin{tabular}{ccccc}
\hline Load (N) & $\boldsymbol{a}$ & $\boldsymbol{b}$ & $\boldsymbol{c}$ & Fitting Degree \\
\hline 10 & 6.28091 & 19.1928 & 0.0002 & 0.99952 \\
20 & 13.4913 & 52.5212 & -0.04617 & 0.98962 \\
30 & 21.6248 & 82.6499 & -0.08171 & 0.98727 \\
40 & 33.9018 & 118.9243 & -0.12183 & 0.97968 \\
50 & 74.8708 & 197.9574 & -0.02264 & 0.98295 \\
\hline
\end{tabular}

When $20 \mathrm{~N}$, the calculated values of six groups of different sliding speeds $(15 \mathrm{~mm} / \mathrm{s}$, $25 \mathrm{~mm} / \mathrm{s}, 35 \mathrm{~mm} / \mathrm{s}, 45 \mathrm{~mm} / \mathrm{s}, 55 \mathrm{~mm} / \mathrm{s}$, and $65 \mathrm{~mm} / \mathrm{s}$ ) in the friction coefficient Equation (2) were calculated to compare with the measured values tested on the CFT-I Friction tester. The results are shown in Table 5, and the errors between the predicted values and the measured values were less than $5 \%$, which thoroughly verified the effectiveness of the new friction model.

Table 5. Comparison between measured values of friction coefficient and calculated values of friction model.

\begin{tabular}{cccc}
\hline Velocity $(\mathbf{m m} / \mathbf{s})$ & Measured Values $(\boldsymbol{\mu})$ & Calculated Values $(\boldsymbol{\mu})$ & Error $(\mathbf{\%})$ \\
\hline 15 & 0.179 & 0.184 & 2.79 \\
25 & 0.139 & 0.142 & 2.16 \\
35 & 0.119 & 0.116 & -2.52 \\
45 & 0.102 & 0.098 & -3.92 \\
55 & 0.082 & 0.085 & 3.66 \\
65 & 0.072 & 0.075 & 4.17 \\
\hline
\end{tabular}


(2) Friction model with average load

Under different speeds $(20 \mathrm{~mm} / \mathrm{s}, 30 \mathrm{~mm} / \mathrm{s}, 40 \mathrm{~mm} / \mathrm{s}, 50 \mathrm{~mm} / \mathrm{s}$, and $60 \mathrm{~mm} / \mathrm{s})$, the curve of friction coefficients with the load $(10 \mathrm{~N}, 20 \mathrm{~N}, 30 \mathrm{~N}, 40 \mathrm{~N}, 50 \mathrm{~N})$ were measured, as shown in Figure 12. The friction coefficient decreased appropriately with the increase in the speed and load. The friction coefficient was modeled according to the changing trend. Based on Zhao [18] and Dou [10], the new friction model was:

$$
\mu=\mu_{0}\left(\frac{F_{n}}{F_{0}}\right)^{a-1}+b
$$

where $\mu$ is the friction coefficient, $F_{0}$ is the reference load; $F_{n}$ is the average load, $\mu_{0}$ is the friction coefficient under the reference load, $A_{0}$ is the model index $\left(F_{0}>0,0.5 \leq a_{0} \leq 1\right)$, and $b_{0}$ is the coefficient. The reference load was $F_{0}=15 \mathrm{~N}$ and measured $\mu_{0}=0.148$.

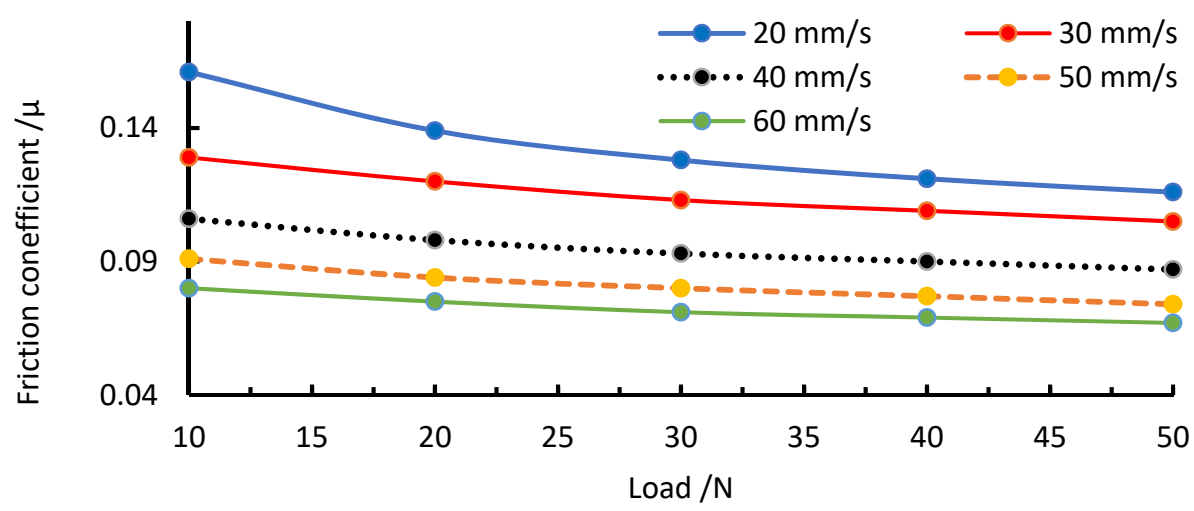

Figure 12. Relationship between friction coefficient and sliding speed.

An inverse function was used to fit with the expression with the Origin software. The fitting results under different sliding speeds $(20 \mathrm{~mm} / \mathrm{s}, 30 \mathrm{~mm} / \mathrm{s}, 40 \mathrm{~mm} / \mathrm{s}, 50 \mathrm{~mm} / \mathrm{s}$, and 60 m/s) are shown in Figure 13.

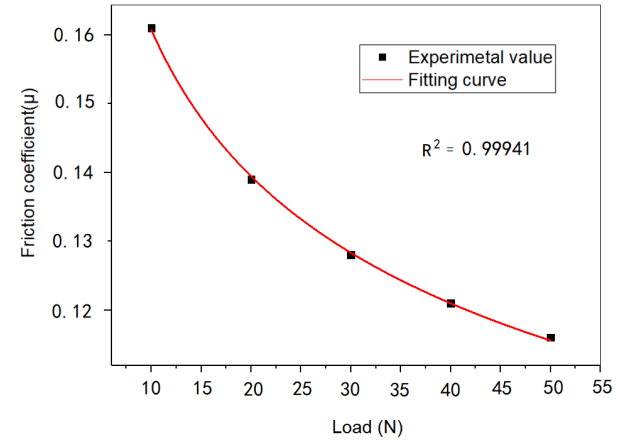

(a)

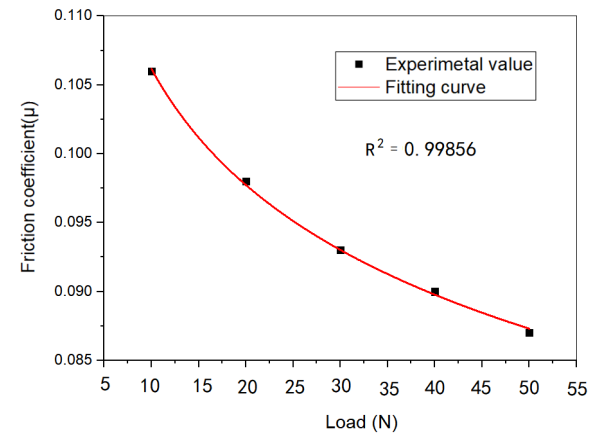

(c)

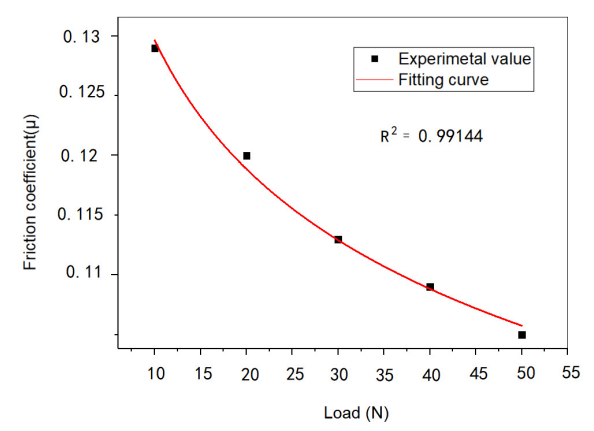

(b)

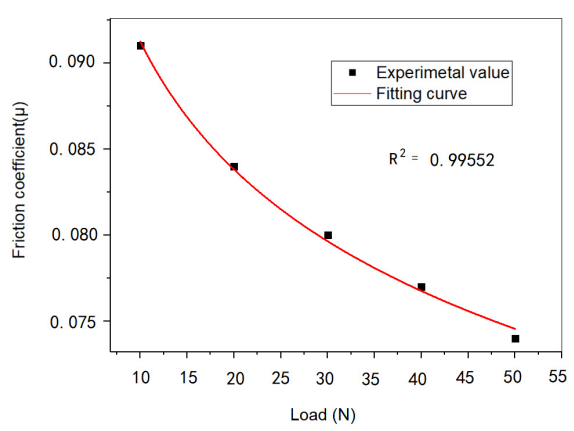

(d)

Figure 13. Cont. 


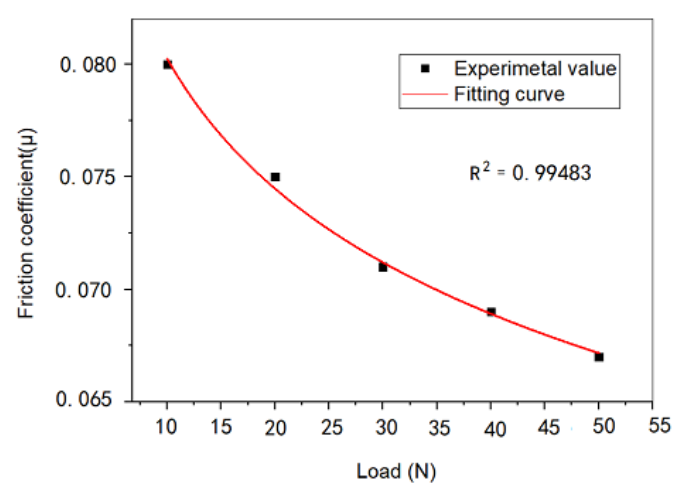

(e)

Figure 13. Friction coefficient curve and function fitting curve under different sliding speeds. (a) $20 \mathrm{~mm} / \mathrm{s}$; (b) $30 \mathrm{~mm} / \mathrm{s}$; (c) $40 \mathrm{~mm} / \mathrm{s}$; (d) $50 \mathrm{~mm} / \mathrm{s}$; (e) $60 \mathrm{~mm} / \mathrm{s}$.

From the fitting curve, the fitting effects were quite good. The values of $a, b$, and the fitting degree were calculated as shown in Table 6. The fitting degrees were more than 0.95 , which meant that the fair values of $a$ and $b$ were practical.

Table 6. Fitting results of $a$ and $b$ under different speeds.

\begin{tabular}{cccc}
\hline Speed/(mm/s) & $\boldsymbol{a}$ & $\boldsymbol{b}$ & Fitting Degree \\
\hline 20 & 0.79523 & -0.0001 & 0.99941 \\
30 & 0.89554 & -0.02476 & 0.99144 \\
40 & 0.91826 & -0.04682 & 0.99856 \\
50 & 0.92796 & -0.06115 & 0.99552 \\
60 & 0.94392 & -0.07116 & 0.99483 \\
\hline
\end{tabular}

The validity of the model was further verified. When the speed was $20 \mathrm{~mm} / \mathrm{s}$, the fitted $a=0.79523, b=0.0001$, and the fitting degree of the function curve was 0.99941 . Therefore, the fitting effect was good, and the relationship function was:

$$
\mu=0.148\left(F_{n} / 15\right)^{-0.20477}-0.0001
$$

Five groups of different speeds $(15 \mathrm{~mm} / \mathrm{s}, 25 \mathrm{~mm} / \mathrm{s}, 45 \mathrm{~mm} / \mathrm{s}, 55 \mathrm{~mm} / \mathrm{s}$, and $65 \mathrm{~mm} / \mathrm{s})$ were selected for measurement and compared with the calculated values of the friction model. As shown in Table 7, the overall errors of models were less than $7 \%$, which proved the effectiveness of the prediction model.

Table 7. Comparison between measured and calculated values of friction model.

\begin{tabular}{cccc}
\hline Load $(\mathbf{N})$ & Measured Value $(\boldsymbol{\mu})$ & Calculated Values $(\boldsymbol{\mu})$ & Error $(\mathbf{\%})$ \\
\hline 5 & 0.179 & 0.185 & 3.24 \\
15 & 0.148 & 0.148 & 0 \\
25 & 0.130 & 0.133 & 2.26 \\
35 & 0.119 & 0.124 & 4.03 \\
45 & 0.115 & 0.118 & 2.54 \\
55 & 0.108 & 0.113 & 4.42 \\
65 & 0.102 & 0.110 & 6.42 \\
\hline
\end{tabular}

(3) Mix friction model with velocity and average load

The experimental data were analyzed by the SPSS software. Since the friction coefficient was a continuous numerical variable, multiple linear regression analyses could have been adopted. The analysis results of the regression equation are as follows in Tables 8 and 9 . 
Table 8. Model summary ${ }^{\mathrm{b}}$.

\begin{tabular}{ccccc}
\hline Model & $\mathbf{R}$ & $\mathbf{R}^{\mathbf{2}}$ & $\mathbf{R}^{\mathbf{2}}$ of after Adjustment & Error in Standard Estimation \\
\hline 1 & $0.974^{\mathrm{a}}$ & 0.948 & 0.943 & 0.005841 \\
\hline
\end{tabular}

a Dependent variable: friction coefficient; ${ }^{b}$ predictive variables: (constant), load, speed.

Table 9. Coefficient ${ }^{\mathrm{a}}$ table.

\begin{tabular}{cccccccc}
\hline Model & $\begin{array}{c}\text { Non Standardized } \\
\text { Coefficient } \\
\text { B Standard Error }\end{array}$ & $\begin{array}{c}\text { Standardization } \\
\text { Coefficient }\end{array}$ & $t$ & Significance & Tolerance VIF \\
\hline Constant & 0.179 & 0.004 & & 41.639 & 0.000 & & \\
Speed & -0.002 & 0.000 & -0.912 & -18.716 & 0.000 & 1.000 & 1.000 \\
Load & -0.001 & 0.000 & -0.340 & -6.937 & 0.000 & 1.000 & 1.000 \\
\hline
\end{tabular}

a Dependent variable: friction coefficient.

The analysis of the results from the chart was as follows: the fitting degree of the friction coefficient regression model $\mathrm{R}^{2}=0.974$ and the appropriate degree of the Equation were good. The significance of the model $p<0.05$ meant that the load and speed variables significantly affected the friction coefficient. The velocity could substantially negatively affect the friction coefficient, and the influence coefficient was $-0.002<0$, significance $p<0.05$. The load could also significantly negatively affect the friction coefficient, and the influence coefficient was $-0.001<0$, significance $p<0.05$, respectively. Additionally, the standard deviation of the regression equation conformed to the normal distribution, as shown in Figure 14.

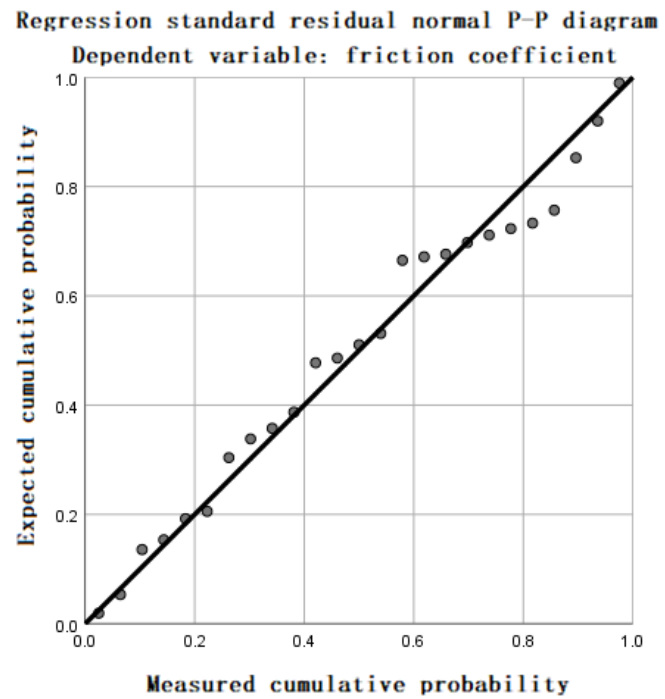

Figure 14. Standard P-P diagram of regression standardized residuals of the model.

Based on the above analysis, the regression equation was:

$$
\mu=0.179-0.002 v-0.001 F
$$

where $v$ is the velocity and $F$ is the load. The absolute value of the standardized regression coefficient of the speed was 0.912 , and the load was 0.340 . Therefore, the influence of speed on the friction coefficient was more potent than that of the load.

\subsection{Application and Verification of Symmetrical Parts}

The friction model was input into the ABAQUS software to verify the effectiveness of the variable friction model in predicting the numerical simulation of symmetrical parts 
stamping. The typical symmetrical part of a U-shape was simulated, and its specific parameters were $30 \mathrm{~mm}$ in width, $50 \mathrm{~mm}$ in length, the fillet radius of the punch and die was $10 \mathrm{~mm}$, the distance between straight wall parts on both sides of the die was $50 \mathrm{~mm}$, the stamping depth was $50 \mathrm{~mm}$, the thickness was $1 \mathrm{~mm}$, and the die gap was $1.1 \mathrm{~mm}$. The U-shaped model is shown in Figure 15.

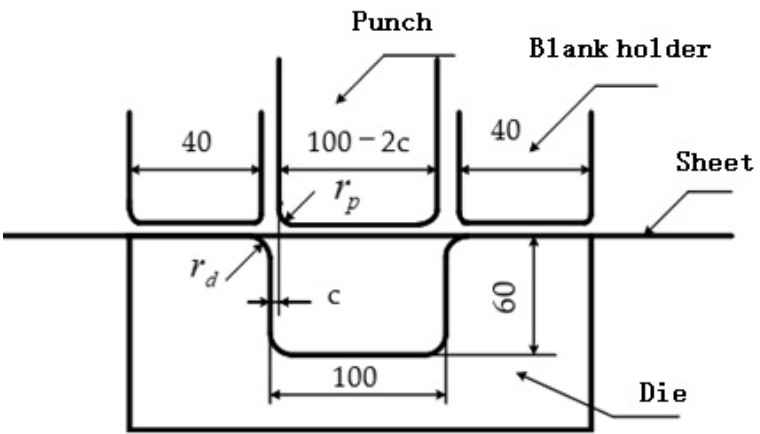

(a)

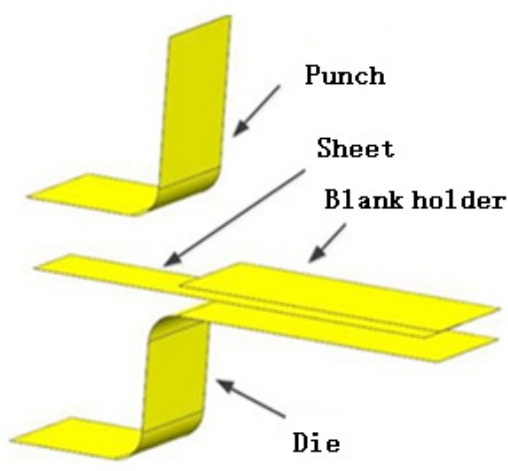

(b)

Figure 15. Numerical model of punch. (a) Two-dimensional drawing; (b) three-dimensional picture.

In the warm stamping simulation, the temperature significantly impacted material properties. The thermal-mechanical coupling analysis method had to follow the flow strain and heat transfer law at warm temperatures. During the simulation, it was necessary to set the nonlinear parameters related to the temperature, such as the elastic modulus, Poisson's ratio, stress-strain, thermal conductivity, specific heat, etc. The physical parameters of the aluminum alloy are shown in Table 10, while the physical parameters of the P20 steel are shown in Table 11.

Table 10. Physical parameters of aluminum alloy AA6061 [17].

\begin{tabular}{|c|c|c|c|c|c|c|}
\hline $\begin{array}{c}\text { Temperature } \\
\left({ }^{\circ} \mathrm{C}\right)\end{array}$ & $\begin{array}{l}\text { Young's } \\
\text { Modulus } \\
\text { (GPa) }\end{array}$ & $\begin{array}{l}\text { Density } \\
\left(\mathrm{kg} / \mathrm{m}^{3}\right)\end{array}$ & $\begin{array}{l}\text { Yield Stress } \\
\text { (MPa) }\end{array}$ & $\begin{array}{c}\text { Thermal } \\
\text { Expansion } \\
(\mu \mathrm{m} /(\mathrm{m} \cdot \mathrm{K}))\end{array}$ & $\begin{array}{c}\text { Thermal } \\
\text { Conductivity } \\
(\mathrm{W} /(\mathrm{m} \cdot \mathrm{K}))\end{array}$ & $\begin{array}{c}\text { Heat Capacity } \\
(\mathrm{J} /(\mathrm{kg} \cdot \mathrm{K}))\end{array}$ \\
\hline 25 & 68.9 & 2700 & 276 & 22 & 167 & 896 \\
\hline 37.8 & 68.54 & 2685 & 274.4 & 23.45 & 170 & 920 \\
\hline 93.3 & 66.19 & 2685 & 264.6 & 24.61 & 177 & 978 \\
\hline 148.9 & 63.09 & 2667 & 248.2 & 25.67 & 184 & 1004 \\
\hline 204.4 & 59.16 & 2657 & 218.6 & 26.6 & 192 & 1028 \\
\hline 260 & 53.99 & 2657 & 159.7 & 27.56 & 201 & 1052 \\
\hline 315.6 & 47.48 & 2630 & 66.2 & 28.53 & 207 & 1078 \\
\hline 371.1 & 40.34 & 2620 & 34.5 & 29.57 & 217 & 1104 \\
\hline 426.7 & 31.72 & 2602 & 17.9 & 30.71 & 223 & 1133 \\
\hline
\end{tabular}

Table 11. Thermophysical parameters of P20 [18].

\begin{tabular}{|c|c|c|c|c|c|}
\hline Density/(kg/m $\left.{ }^{3}\right)$ & $\begin{array}{l}\text { Poisson's } \\
\text { Ratio }\end{array}$ & $\begin{array}{c}\text { Yield } \\
\text { Stress/(MPa) }\end{array}$ & $\begin{array}{c}\text { Thermal } \\
\text { Expansion } /(\mu \mathrm{m} /(\mathrm{m} \cdot \mathrm{K}))\end{array}$ & $\begin{array}{c}\text { Thermal } \\
\text { Conductivity } /(W /(m \cdot K))\end{array}$ & $\begin{array}{c}\text { Specific Heat } \\
\text { Capacity/(J/(kg.K)) }\end{array}$ \\
\hline $7.81 \times 10^{3}$ & 0.275 & 836 & 12.8 & 35.7 & 460 \\
\hline
\end{tabular}

In ABAQUS, we set the symmetrical part as the shell and isotropic homogeneous material. The tool material attribute was solid, and the material was homogeneous. The dynamic coupling analysis algorithm was selected to turn on geometric nonlinearity. Under the condition of the hot forming of parts, the selection of stamping process parameters is in Table 12. The displayed thermal-mechanical coupling model was selected as the analysis model. Refer to Table 12 for input values when inputting the simulation process parameters. 
Table 12. The simulation process parameters of warm stamping.

\begin{tabular}{cccccc}
\hline $\begin{array}{c}\text { Sheet } \\
\text { Temperature } \\
\left({ }^{\circ} \mathbf{C}\right)\end{array}$ & $\begin{array}{c}\text { Holding Time } \\
(\mathbf{m i n})\end{array}$ & $\begin{array}{c}\text { Tooling } \\
\text { Temperature } \\
\left({ }^{\circ} \mathbf{C}\right)\end{array}$ & $\begin{array}{c}\text { Transfer Time } \\
(\mathbf{s})\end{array}$ & $\begin{array}{c}\text { Blank Holder } \\
\text { Force (N) }\end{array}$ & $\begin{array}{c}\text { Punch Pressure (MPa) } \\
\text { Pounch Speed } \\
(\mathbf{m m} / \mathbf{s})\end{array}$ \\
\hline 200 & 4 & 60 & 3 & 30 & 3.0 \\
\hline
\end{tabular}

When setting process parameters, we selected the "power/temperature displacement/explicit" type in the finite element analysis. In the first step, the blank holder moved downward, and in the second step, the punch moved downward and the blank holder kept still. Different friction coefficient conditions were introduced into the simulation softly. Thermal conductivity values were input from Table 10; the natural convection coefficient between the sheet and the air was $29 \mathrm{~W} / \mathrm{m}^{2} / \mathrm{K}$, and the heat exchange coefficient between the tool and cooling water was $1200 \mathrm{~W} / \mathrm{m}^{2} / \mathrm{K}$. The die surface was the master surface, and the blank surface was the slave surface; three reference points were set by "rigid body" and constrained the punch, die, and blank holder. The boundary condition was set by the displacement/rotation angle type and fixed. In the first step, the holder moved down $20 \mathrm{~mm}$, and the amplitude type was a smooth analysis. In the second step, the punch moved downward $60 \mathrm{~mm}$; the blank temperature was $200{ }^{\circ} \mathrm{C}$ and the die temperature was $25^{\circ} \mathrm{C}$. The grid shape was tetrahedral, the element type was temperature displacement coupling, and the grid number was 18654.

According to reference [11], there are three types of lubrication for sheet forming: fluid lubrication $(\mu \leq 0.03)$, mixed lubrication $(0.03<\mu \leq 0.1)$, and boundary lubrication $(0.1<\mu<0.3)$. The friction states were mostly boundary lubrication and mixed lubrication in the actual stamping process. Therefore, four types were selected for simulation: a constant friction coefficient of 0.12 (boundary lubrication), velocity friction model, load friction model, and mixed friction model. The variable friction coefficient model passed through the user subroutine "fric_coef" of ABAQUS. Figure 16 shows the thickness distributions cloud diagrams with different friction conditions.
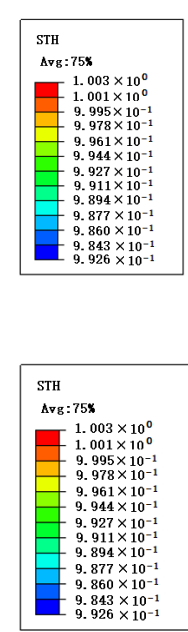

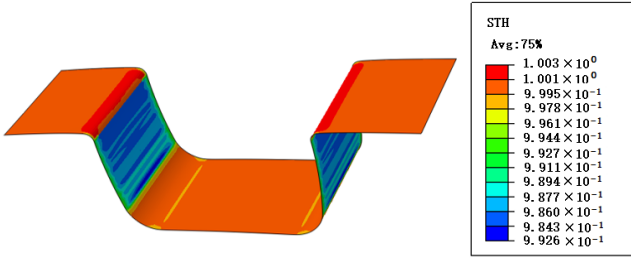

(a)

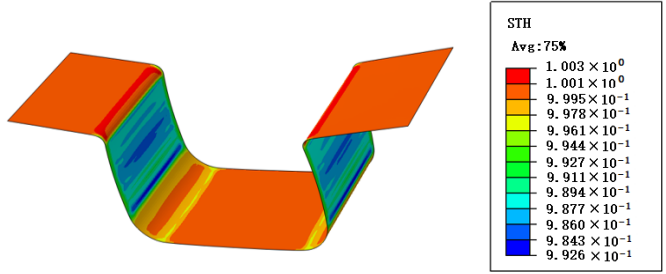

(c)

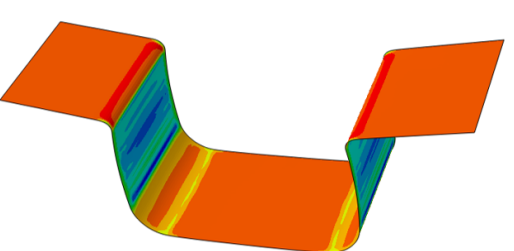

(b)

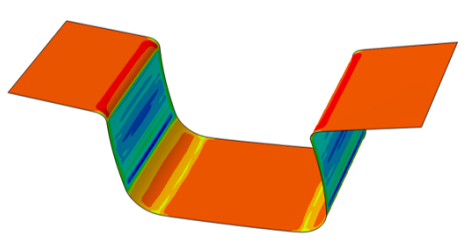

(d)

Figure 16. Diagram of thickness distribution. (a) $\mu=0.12$; (b) velocity friction model; (c) load friction model; (d) mix friction model.

An actual warm forming stamping test was carried out after the finite element simulation. The test device included a temperature detection and control system, induction heating furnace, water-cooled U-shaped warm stamping die, hydraulic press, etc., as shown in Figure 17a. The temperature control system used an infrared thermometer to heat the plate temperature and die surface temperature, and controlled the temperature 
through cooling water. After heating the induction furnace, we performed the experiments quickly. The die was P20 steel without heating, cooled by a cooling water pipe. The formed U-shaped parts are shown in Figure 17b.

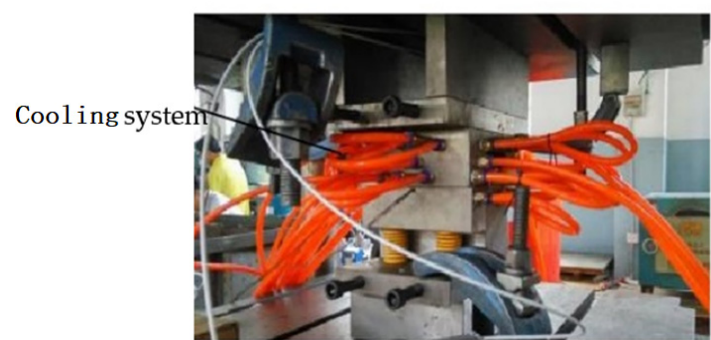

(a)

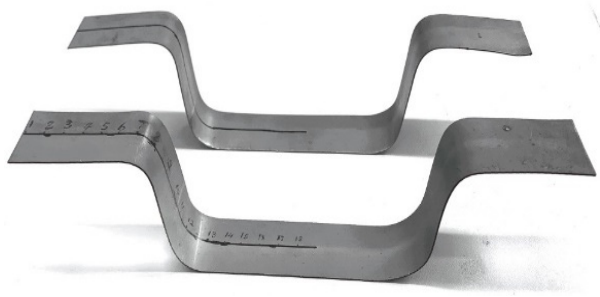

(b)

Figure 17. Warm stamping experimental device: (a) warm stamping mold; (b) hot stamping part.

(1) Thickness analysis of symmetrical part (U-Bend)

For warm stamping symmetrical parts, the thickness of the actual stamping parts was measured with a micrometer, and 18 measuring points were the symmetrical center in the plate width direction. The thickness distribution curve was determined by a constant friction coefficient $(0.08,0.12)$, variable friction coefficient model, and actual measured values, as shown in Figure 18. We found that the thickness distribution of the variable friction models was closer to the actual values.

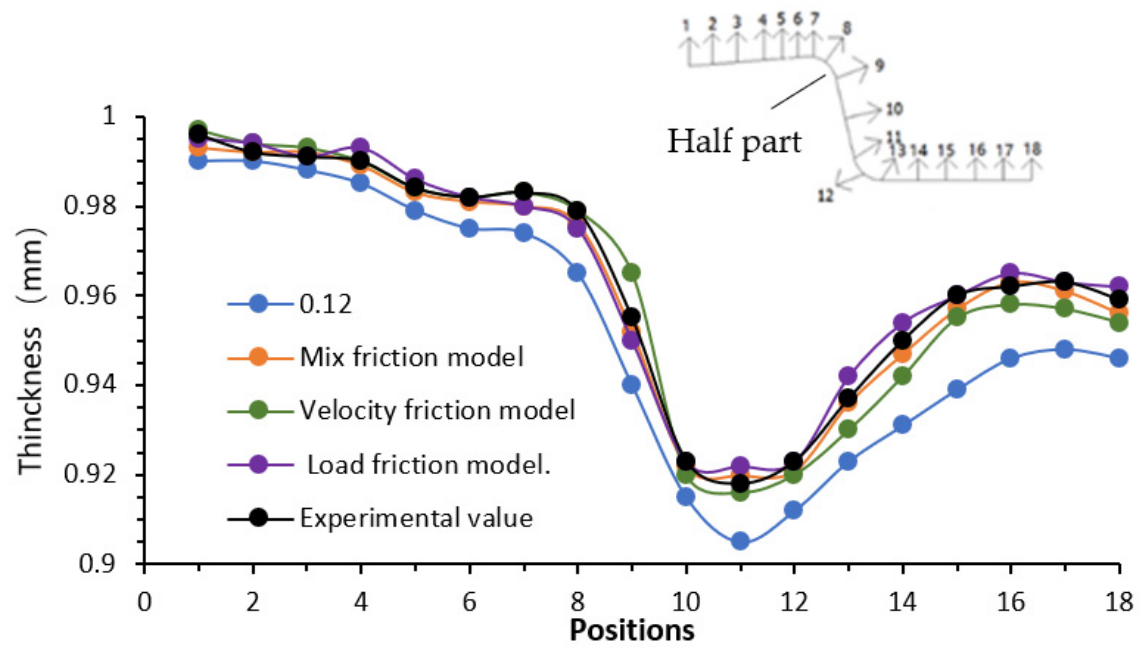

Figure 18. The thickness distribution curve of half of the symmetrical part.

(2) Springback analysis of symmetrical part

The springback of the symmetrical part reflected the error between the actual value and the design value. The smaller the springback was, the better the accuracy was. We selected a constant friction coefficient of 0.12 , and variable friction coefficient models for the simulation analysis and measured the springback angle after bending. The definition of the springback angle is shown in Figure 19a. The flange bending angle was $\theta_{1}$ and sidewall bending angle was $\theta_{2}$; the corresponding springback angles were $\Delta \theta_{1}=90^{\circ}-\theta_{2}$ and $\Delta \theta_{1}=90^{\circ}-\theta_{1}$ respectively. The measurement values and simulation results of different friction models are shown in Figure 19b. We measured five times to reduce the measurement error, and the average values were taken as the practical values; $6.7^{\circ}$ and $-7.2^{\circ}$, respectively. In the ABAQUS simulation post-processing, the springback under constant friction coefficient of 0.12 was $5.6^{\circ}$ and $-6.2^{\circ}$, respectively. The errors with the actual values were $16.4 \%$ and $13.9 \%$, respectively. With the mix friction coefficient model, 
the springback was $5.6^{\circ}$ and -6.2 , and the errors were $3.0 \%$ and $4.2 \%$; with the speed friction model, the springback was $6.4^{\circ}$ and $-6.9^{\circ}$, and the errors were $4.5 \%$ and $4.2 \%$; when the load friction model was used, the springback was $6.3^{\circ}$ and $-6.8^{\circ}$, and the errors were $6.0 \%$ and $6.5 \%$, as shown in Table 13 . Therefore, the mix friction model value was closer to the actual value than the others, reflecting the friction characteristics.

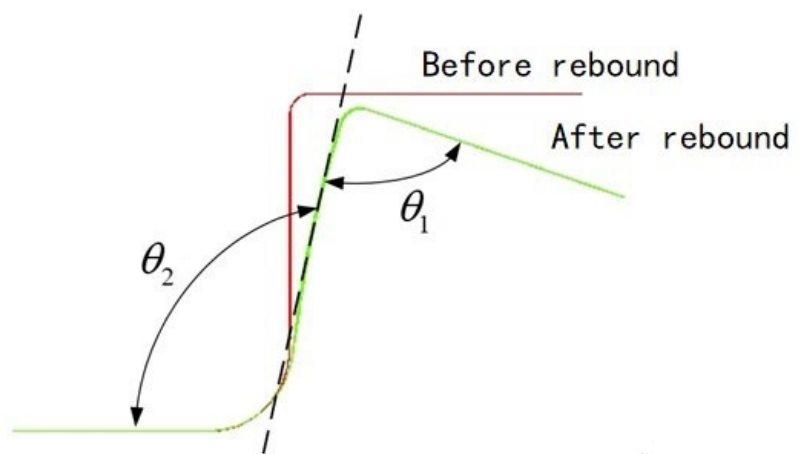

(a)

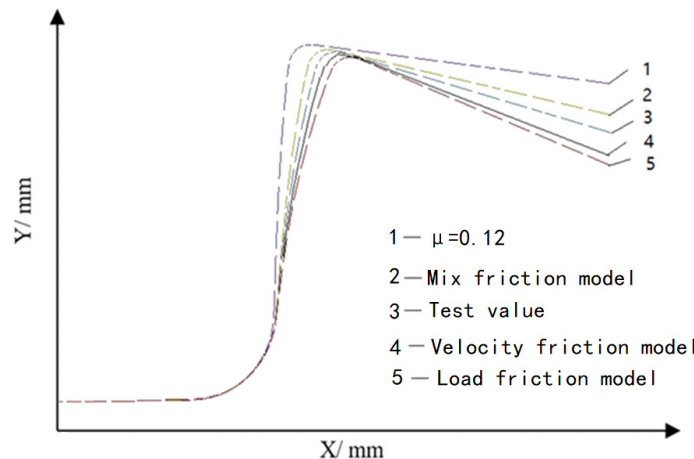

(b)

Figure 19. Springback: (a) springback angle; (b) springback angle measurement under different friction coefficients.

Table 13. Simulation and measurement of springback angle $\left(^{\circ}\right)$.

\begin{tabular}{cccccc}
\hline $\begin{array}{c}\text { Springback Angle } \\
\left({ }^{\circ}\right)\end{array}$ & Measured Values & $\begin{array}{c}\text { Constant Friction } \\
\text { Coefficient (0.12) }\end{array}$ & $\begin{array}{c}\text { Mix Friction } \\
\text { Mode }\end{array}$ & $\begin{array}{c}\text { Speed Friction } \\
\text { Model }\end{array}$ & $\begin{array}{c}\text { Load Friction } \\
\text { Model }\end{array}$ \\
\hline$\Delta \theta_{1}$ & 6.7 & $5.6($ error $16.4 \%)$ & $6.5($ error $3.0 \%)$ & $6.4($ error $4.5 \%)$ & $6.3($ error $6.0 \%)$ \\
$\Delta \theta_{2}$ & -7.2 & $-6.2($ error $13.9 \%)$ & $-6.9($ error $4.2 \%)$ & $-6.9($ error $4.2 \%)$ & $-6.8($ error $5.6 \%)$ \\
\hline
\end{tabular}

\section{Conclusions}

The friction properties of the AA6061 aluminum alloy and P20 steel were tested by the CFT-I friction tester under different temperatures, sliding speed, and normal load. Variable friction coefficient models based on the sliding speed and normal load were established and validated. The surface morphology was observed and analyzed. The results were as follows:

(1) The friction coefficient increased with the temperature, the increasing trend slowed down, and it tended to be stable with time; the friction coefficient decreased with speed and the load growth. Surface scratches increased and deepened with the interfacial load and sliding speed increase. The surface morphology changed with the rise of temperature and the quality was good at $200{ }^{\circ} \mathrm{C}$; this was a warm forming temperature.

(2) The variable friction coefficient models of sliding speed and load were established through an analysis, of which the fitting was good, with errors less than $5 \%$ and $7 \%$, respectively. The results showed the new friction models had a better accuracy.

(3) The stamping simulation of the symmetrical U-Bend parts used the variable friction coefficient model established by the finite element analysis software and friction test. The simulation analysis results showed that the thickness distribution and springback of variable friction coefficient models were less than the constant friction coefficient (less than $6 \%$ ). The mix friction model value was closer to the actual value. Therefore, the variable friction coefficient models could improve the simulation accuracy. 


\begin{abstract}
Author Contributions: Conceptualization, J.X. and S.D.; methodology, J.X.; software, S.D.; validation, J.X.; formal analysis, J.X.; investigation, J.X.; resources, J.X.; data curation, S.D.; writing-original draft preparation, J.X.; writing—review and editing, J.X.; visualization, J.X.; supervision, J.Z.; project administration, J.Z.; funding acquisition, J.Z. All authors have read and agreed to the published version of the manuscript.
\end{abstract}

Funding: China's National Natural Science Foundation (51975509).

Institutional Review Board Statement: Not applicable.

Informed Consent Statement: Not applicable.

Data Availability Statement: Not applicable.

Conflicts of Interest: The authors declare no conflict of interest.

\title{
References
}

1. Hosseini-Tehrani, P.; Nikahd, M. Two materials S-frame representation for improving crashworthiness and lightening. Thin-Walled Struct. 2006, 44, 407-414. [CrossRef]

2. Hyung, J.K.; Collin, M.M.; Keoleian, G.A. Greenhouse gas emissions payback for lightweight vehicles using aluminum and high-strength steel. J. Ind. Ecol. 2010, 14, 929-946.

3. Mendiguren, J.; de Argandona, E.S.; Galdos, L. Hot stamping of AA7075 aluminum sheets. In IOP Conference Series: Materials Science and Engineering, Proceedings of the IDDRG2016 Conference on "Challenges in Forming High-Strength Sheets", Linz, Austria, 12-15 June 2016; IOP Publishing Ltd.: Bristol, UK, 2016; Volume 159, pp. 12-226.

4. $\quad$ Dong, Y.C.; Zheng, K.L.; Fernandez, J.; Li, X.Y.; Dong, H.S.; Lin, J.G. Experimental investigations on hot forming of AA6082 using advanced plasma nitrocarburized and CAPVD WC: C coated tools. J. Mater. Process Technol. 2017, 240, 190-199. [CrossRef]

5. Yu, Q.; Liang, J.; Li, Q.; Li, C. Development of Measurement Equipment and Experimental and Numerical Simulation Studies for Warm Forming Limits of High-Strength Steel. Materials 2021, 14, 2373. [CrossRef] [PubMed]

6. Kondratiuk, J.; Kuhn, P. Tribological investigation on friction and wear behaviour of coatings for hot sheet metal forming. Wear 2011, 270, 839-849. [CrossRef]

7. Dou, S.S.; Xia, J.S. Analysis of sheet metal forming (stamping process): A study of the variable friction coefficient on 5052 aluminum alloy. METALS 2019, 9, 853. [CrossRef]

8. Han, S. The influence of tool geometry on friction behavior in sheet metal forming. J. Mater. Process. Technol. 1997, 63, 129-133. [CrossRef]

9. Gil, I.; Mendiguren, J.; Galdos, L.; Mugarra, E.; de Argandoña, E.S. Influence of the pressure dependent coefficient of friction on deep drawing springback predictions. Tribol. Int. 2016, 103, 266-273. [CrossRef]

10. Dou, S.S.; Wang, X.P. Analysis of Sheet Metal Forming (Warm Stamping Process): A Study of the Variable Friction Coefficient on 6111 Aluminum Alloy. METALS 2020, 10, 1189. [CrossRef]

11. Dohda, K.; Boher, C.; Rezai-Aria, F.; Mahayotsanun, N. Tribology in metal forming at elevated temperatures. Friction 2015, 3, 1-27. [CrossRef]

12. Marzouki, M.; Kowandy, C.; Richard, C. Experimental simulation of tool/product interface during hot drawing. Wear 2007, 262, 235-241. [CrossRef]

13. Matuszak, A. Factors influencing friction in steel sheet forming. J. Mater. Process. Technol. 2000, 106, 250-253. [CrossRef]

14. Ahmad, R.; Asmael, M.B.A. Effect of aging time on microstructure and mechanical properties of AA6061 friction stir welding joints. Int. J. Automot. Mech. Eng. 2015, 11, 2364-2372. [CrossRef]

15. Chowdhury, M.A.; Helali, M.M. The frictional behavior of mild steel under horizontal vibration. Tribol. Int. 2009, 42, 946-950. [CrossRef]

16. Riahi, M.; Nazari, H. Analysis of transient temperature and residual thermal stresses in friction stir welding of aluminum alloy 6061-T6 via numerical simulation. Int. J. Adv. Manuf. Technol. 2011, 55, 143-152. [CrossRef]

17. Babić, M.; Mitrović, S.; Ninković, R. Tribological Potential of Zinc-Aluminum Alloys Improvement. Tribol. Ind. 2009, 31, 15-28.

18. Zhao, Y.Z.; Wang, K.; Wang, W.R. Application of Variable Friction Coefficient Model in Forming of Advanced High-Strength Steel. J. Shanghai Jiao Tong Univ. 2015, 10, 1146-1451. 